\title{
Aerobic Physical Exercise Improved the Cognitive Function of Elderly Males but Did Not Modify Their Blood Homocysteine Levels
}

\author{
Hanna Karen M. Antunes ${ }^{a, c}$ Marco Túlio De Mellob, $c$ \\ Valdir de Aquino Lemos, c Ruth Ferreira Santos-Galduróz ${ }^{\mathrm{b}}$

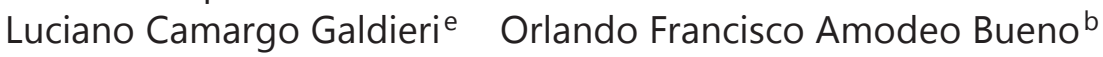 \\ Sergio Tufik ${ }^{\mathrm{b}}$ Vânia D'Almeida ${ }^{\mathrm{b}}$ \\ a Departamento de Biociências, Universidade Federal de São Paulo - UNIFESP, Santos,

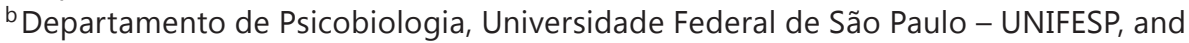 \\ ${ }^{c}$ Centro de Estudos em Psicobiologia e Exercício - CEPE, São Paulo, and d Centro de \\ Matemática, Computação e Cognição, Universidade Federal do ABC - UFABC, Santo André, \\ Brazil; 'St. John's University, Queens, New York, N.Y., USA
}

\section{Key Words}

Homocysteine - Cognitive function - Physical exercise - Elderly subjects - Aerobic training ·

Metabolic profile

\section{Abstract}

Background: Physical exercise influences homocysteine (Hcy) concentrations, cognitive function and the metabolic profile. The purpose of this study was to investigate the influence of regular physical exercise on Hcy levels, the metabolic profile and cognitive function in healthy elderly males before and after an endurance exercise program. Methods: Forty-five healthy and sedentary volunteers were randomized into 2 groups: (1) a control group asked not to change their normal everyday activities and not to start any regular physical exercise program and (2) an experimental group trained at a heart rate intensity corresponding to ventilatory threshold 1 (VT-1) for $60 \mathrm{~min} /$ day 3 times weekly on alternate days for 6 months using a cycle ergometer. All volunteers underwent cognitive evaluations, blood sample analyses and ergospirometric assessments. Results: A significant improvement in cognitive function was observed in the experimental group compared with the control group $(p<0.05)$. No significant changes in Hcy levels were observed in the experimental group ( $p>0.05)$, but there was a significant increase in peak oxygen consumption and workload at VT-1 as well as a significant improvement in cholesterol, triglycerides, $H D L$, glucose, alkaline phosphatase, urea, $T_{3}, T_{4}$ and prostate-specific antigen compared with the control group $(p<0.05)$. Conclusion: The data suggest that a physical exercise program does not reduce Hcy levels in healthy elderly males, although it improves the cardiovascular and metabolic profile as well as cognitive function. 
Antunes et al.: Aerobic Physical Exercise Improved the Cognitive Function of Elderly Males but Did Not Modify Their Blood Homocysteine Levels

\section{Introduction}

Homocysteine (Hcy) is a sulfhydryl amino acid derived from the metabolism of methionine, an essential amino acid. It can be transsulfurated to cysteine through a pyridoxinedependent pathway or remethylated to methionine through pathways that are dependent on folates, cobalamin and betaine [1].

Hcy concentrations are determined by an interaction between genetic, physiological and environmental factors; elevated Hcy concentrations are related to smoking, coffee and alcohol consumption, insufficient nutrition, a sedentary lifestyle and the intake of certain drugs [2].

There is evidence suggesting that high levels of plasma Hcy are a risk factor for vascular disease [3], fetal malformations, the development of arteriosclerosis, stroke [4], oxidative stress [5] as well as peripheral vascular and cerebrovascular diseases [6]. Elevated Hcy may also have direct toxic effects on central nervous system neurons [7], but it is still debated whether these signs are caused by Hcy or whether elevated Hcy is secondary, that is, a result of these processes [8].

Some reports associate higher Hcy concentrations with Alzheimer's disease [9, 10], psychogeriatric disorders other than dementia [11], mild cognitive impairment without dementia [12] and poorer cognitive performance in normal aging [13]. The mechanisms involved in these associations are not clearly understood [10], but particularly in the elderly, these alterations affect the quality of life mainly by restricting social life and gradually reducing independence.

A previous study has suggested that physical exercise influences Hcy concentrations [14], but many of the results reported are inconclusive, since they involve only the effects of acute exercise; another study showed no significant alterations [15]. On the other hand, a further study showed that physical exercise can lead to enhanced cognitive function in terms of memory, attention, reasoning and praxis [16].

In view of the incongruity of the literature, the present study sought to investigate the influence of regular physical exercise on Hcy concentrations, the metabolic profile and cognitive function in healthy elderly males before and after an endurance exercise program.

\section{Methods}

\section{Participants}

The sample initially consisted of 118 volunteers; however, only 45 healthy sedentary male volunteers aged 60-75 years ended the experiment, and they were randomly distributed into 2 groups: a control group $(n=23)$ and an experimental group $(n=22)$, whose demographic data, presented as means $\pm \mathrm{SD}$, are shown in table 1 .

Prior to the procedure, we performed medical evaluations including electrocardiograms at rest and with effort to assess cardiovascular parameters. The diet was not monitored, and the subjects continued their own eating routines 'ad libitum'. The volunteers were selected via radio, TV, magazine and newspaper advertisements. All of them were nonsmoking, had no clinical symptoms or indicators of cardiovascular disease, did not take any medication that could alter cardiovascular and cognitive function or plasma Hcy concentrations, did not use alcohol or psychotropic drugs, had a sedentary lifestyle (i.e. no habitual physical activity routine) as evaluated with a short questionnaire for the measurement of habitual physical activity [17] and by oxygen uptake analysis, had no impaired renal function or current liver disease (according to clinical examinations) and had had no surgical intervention in the previous year. 
Antunes et al.: Aerobic Physical Exercise Improved the Cognitive Function of Elderly Males but Did Not Modify Their Blood Homocysteine Levels

Table 1. Characteristics of the sample

\begin{tabular}{lcc}
\hline Variables & Control group & Experimental group \\
\hline Age, years & $66.00 \pm 3.84$ & $68.09 \pm 5.49$ \\
Weight, kg & $77.02 \pm 10.94$ & $77.56 \pm 13.46$ \\
Height, m & $1.68 \pm 0.06$ & $1.69 \pm 0.09$ \\
BMI & $27.83 \pm 3.07$ & $27.06 \pm 3.76$ \\
\hline
\end{tabular}

\section{Experimental Design}

All procedures were approved by the Research Ethics Committee at the Universidade Federal de São Paulo/Hospital São Paulo (207/01). The nature of the study, its aims and possible risks were carefully explained to all volunteers beforehand, and they signed consent forms.

The volunteers of the control group were asked not to vary their everyday activities or join a fitness program. All were monitored longitudinally through monthly phone calls to maintain contact and keep them informed of the course of the study. They were also informed that although they would not be taking part in the fitness program, they would be invited to do so after the intervention period of the experimental group.

The experimental group took part in an aerobic fitness program on alternate days (3 times a week) for 6 months. The sessions were continuous (with the initial duration of $20 \mathrm{~min}$ gradually increasing to a maximum of $60 \mathrm{~min}$ ) and conducted on a cycle ergometer (LifeCycle 9500HR; Life Fitness, Schiller Park, Ill., USA) after an ergospirometric evaluation [ventilatory threshold 1 (VT-1)] of variations in the subjects' heart rates. The workload was adjusted according to the principles of the training; we investigated the relationship between volume and intensity. In all sessions, all volunteers had their arterial pressure checked and their heart frequency monitored using a Polar ${ }^{\circledR}$ Advantage NV device (Polar Electro, Kempele, Finland). The intensity of the exercise was determined according to the concept of an 'anaerobic threshold' $[18,19]$.

A thorough neuropsychological assessment was carried out on 2 occasions: before and after the 6-month physical exercise program. A summary of the experimental design is shown in figure 1.

Physical Evaluation

Exercise Test. By cardiopulmonary assessment, exhaled gases were analyzed with direct measurement of oxygen consumption $\left(\mathrm{VO}_{2}\right)$ to determine the VT. This test determined the following variables: peak $\mathrm{VO}_{2}$, VT-1, maximum ventilation, maximum heart rate as well as heart rate and workload at VT-1 intensity. Respiratory and metabolic variables were obtained by measuring respiratory gaseous exchanges (SensorMedics $V_{\max } 29$ Series Metabolic Measurement Cart; SensorMedics, Yorba Linda, Calif., USA). The system was calibrated before the test using known gas concentrations $\left(\mathrm{O}_{2}\right.$ and $\left.\mathrm{CO}_{2}\right)$, and the flow calibration was carried out using a 3-liter syringe. This system uses a turbine-type flow linearized by the software to measure lung ventilation. It operates through a mixture chamber, with the sample being analyzed continually to determine exhaled fractions of $\mathrm{O}_{2}$ and $\mathrm{CO}_{2}$ at 20-second intervals (SensorMedics software). A Hans Rudolph flow-by face mask (Hans Rudolph Inc., Kansas City, Mo., USA) was positioned on the subjects. Testing was performed on a cycle ergometer (LifeCycle 9500HR). The procedure involved 25-watt load increments every 2 min; the initial warm-up load was $3 \mathrm{~min}$ at $25 \mathrm{~W}$, and the test was terminated upon reaching the safety margin for peak $\mathrm{VO}_{2}$. Blood pressure was monitored during testing (manual sphygmomanometry), and heart rate was monitored using a Polar Advantage NV device at 5-second 


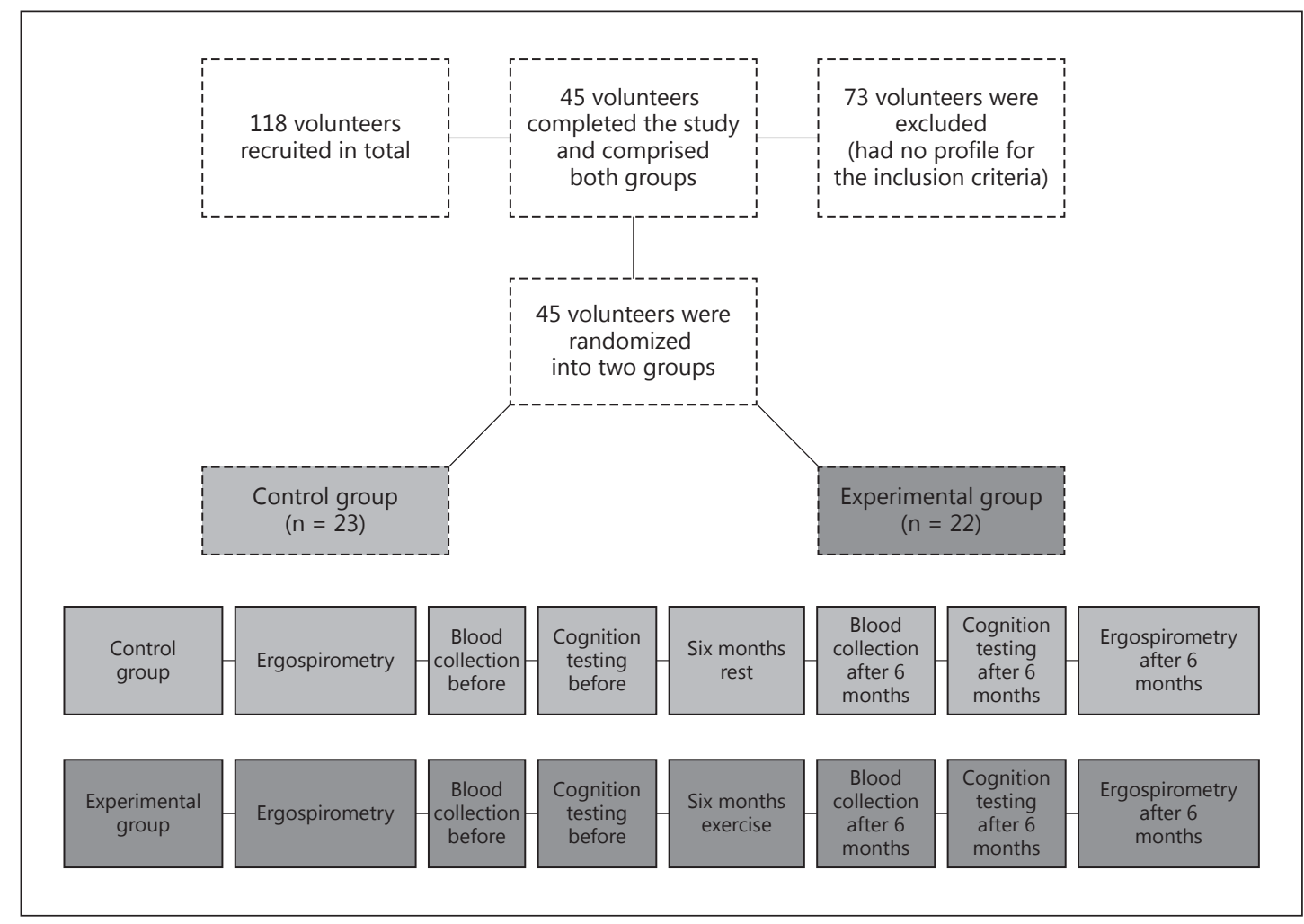

Fig. 1. Summary of the experimental design. The volunteers $(n=45)$ were randomized into 2 groups: a control group $(n=23)$ and an experimental group $(n=22)$.

intervals. The tests were conducted at the same time of day (8-11 a.m.) in an acclimatized and standardized laboratory environment. The classic criteria were used to determine $\mathrm{VO}_{2}$ at VT-1 [20-22].

\section{Cognitive Evaluation}

Digit Span Numbers. This test evaluated the concentrated attention and mental control of the volunteers and consisted of 2 stages. In the first stage, individuals were instructed to repeat a sequence of numbers (direct digits), and in the second part, they were required to listen to a sequence of numbers and repeat them in reverse order (inverse digits) [23].

Similarities Test. This test evaluated verbal comprehension. The volunteers were asked in what way 2 words (objects or concepts) are alike, for instance, 'how are a poem and a statue alike?' The more subjects are capable of abstraction, the higher they will score in the Similarities Test. Following this scoring principle, an answer such as 'they are both artworks' receives the most points ( 2 points); an answer like 'a representation of something' is worth 1 point, and an answer like 'the poem describes the statue' results in 0 points [23].

BlockDesign. This test evaluated spatial/visual orientation, speed of execution, perceptual integration, capacity of planning and organization. A series of 9 geometric designs were presented to the subjects, which they reproduced one at a time with a set of red and white blocks. The latter confronted subjects with 1 of 3 uppercase letters (F, L or R) that were rotated from 0 to $180^{\circ}$ either in normal or mirrored (i.e. backward) orientation [23].

Digit Symbol. This test evaluated sustained attention, response speed and visuomotor coordination. The participants are given a key grid of numbers and matching symbols as well 
Antunes et al.: Aerobic Physical Exercise Improved the Cognitive Function of Elderly Males but Did Not Modify Their Blood Homocysteine Levels

as a test section with numbers and empty boxes. The test consists of filling in as many empty boxes as possible with a symbol matching each number. Ninety seconds were given to complete the task. The score was computed as the number of correctly substituted symbols within the 90-second time frame [23].

Mental Control. This test evaluated the retrieval of learned information and the mental manipulation of information. In addition to the 3 tasks that comprise the mental control subtest (i.e. counting backward from 20 to 1, reciting the alphabet and adding serial 3s), it includes 4 additional tasks: reciting the months of the year forward and backward, an alphabet rhyming task requiring patients to identify letters that rhyme with the word 'key' and an alphabet visualization task requiring volunteers to provide all block-printed letters that contain curved lines [23].

Rey-Osterrieth Complex Figure Test. This test evaluates the executive aspects of the ability of copying a complex figure and praxis as well as immediate and delayed recall of visual stimuli. It consists of the subtests of copying, immediate recall and 20-min delayed recall of a complex figure. The Rey-Osterrieth Complex Figure (ROCF) test performances were scored by 2 clinical psychologists using the Boston Qualitative Scoring System (BQSS) [24].

Wisconsin Card Sorting Test. The Wisconsin Card Sorting Test-64 (WCST-64) evaluates executive function. This test includes 4 stimulation cards and 64 response cards. Each $8 \times 8$ cm card contains 1-4 figures such as triangles, stars, squares and circles, which are colored red, green, yellow and blue, respectively. The subjects were only told that they were 'correct' or 'wrong' when they sorted the cards without knowing the principle of classification, and the principle would be changed when they had 8 consecutive correct answers. The order was color-shape-number-color, and so on. In this study, we considered the number of correct responses [25].

Toulouse-Piéron Test for Concentrated Attention. This test evaluates concentrated attention, reaction speed and accuracy in executing simple tasks. This tool helps in the investigation of 3 areas related to attention: indices of correct response, no response plus wrong response in executing the test and the time taken to complete the test [26].

\section{Laboratory Analysis}

Blood Samples. Morning blood collection was conducted by surface puncture of the forearm vein, with the volunteers remaining in a seated position and after $12 \mathrm{~h}$ of fasting (both collections before and after the period of study; after training). Total Hcy concentrations were determined by high-performance liquid chromatography (Shimadzu, Kyoto, Japan) with fluorimetric detection and isocratic elution [27]. All reagents were obtained from Sigma Chemical Corporation (St. Louis, Mo., USA). The total Hcy content was calculated with a calibration curve using known Hcy concentrations and cystamine as the internal standard.

Screening of the disease was performed by biochemical and hematological tests including assessments of glucose, uric acid, alkaline phosphatase, bilirubin, creatinine, platelets, hemoglobin, hematocrit, thyroid hormones $\left(\mathrm{T}_{3}, \mathrm{~T}_{4}\right)$, lipids (LDL, HDL, triglycerides, VLDL) and prostate-specific antigen (PSA).

\section{Statistical Analysis}

Statistical analysis was performed using Statistics for Windows ${ }^{\circledR}$ version 7.0. To determine the effect of intervention periods (time effect), ANOVA for repeated measurement was used, followed by the Duncan post hoc test; the t test was also used for independent groups. The minimum significance level was set at $5 \%$, and data are presented as means \pm SD or means \pm SE when necessary. 
Table 2. Effect of physical exercise on cognitive function

\begin{tabular}{|c|c|c|c|c|}
\hline \multirow[t]{2}{*}{ Variables } & \multicolumn{2}{|l|}{ Control group } & \multicolumn{2}{|c|}{ Experimental group } \\
\hline & baseline & $\begin{array}{l}\text { after } \\
\text { intervention }\end{array}$ & baseline & $\begin{array}{l}\text { after } \\
\text { intervention }\end{array}$ \\
\hline Digit symbol & $36.41 \pm 18.59$ & $29.64 \pm 8.00^{*}$ & $32.48 \pm 11.21$ & $38.87 \pm 8.03^{*}$ \\
\hline Similarities test & $17.68 \pm 3.81$ & $18.55 \pm 2.77$ & $17.09 \pm 3.82$ & $18.48 \pm 2.94^{*}$ \\
\hline Mental control & $5.05 \pm 1.17$ & $5.36 \pm 0.90$ & $5.04 \pm 1.30$ & $5.52 \pm 0.85$ \\
\hline Picture arrangement & $8.77 \pm 2.79$ & $9.50 \pm 3.20$ & $9.65 \pm 4.79$ & $11.70 \pm 2.75^{*}$ \\
\hline Block design & $18.32 \pm 7.43$ & $18.82 \pm 5.59$ & $17.91 \pm 12.66$ & $23.83 \pm 9.61^{*}$ \\
\hline \multicolumn{5}{|l|}{ ROCF test } \\
\hline Copy & $32.20 \pm 3.76$ & $33.0 \pm 2.9$ & $32.09 \pm 4.12$ & $33.24 \pm 2.33$ \\
\hline Immediate recall & $11.68 \pm 6.97$ & $13.0 \pm 7.4$ & $14.50 \pm 7.61$ & $16.33 \pm 7.01 *$ \\
\hline Delayed recall & $11.91 \pm 6.94$ & $12.4 \pm 7.7$ & $13.35 \pm 7.70$ & $15.24 \pm 7.37$ \\
\hline \multicolumn{5}{|l|}{ Digit span } \\
\hline Forward & $5.73 \pm 2.31$ & $5.64 \pm 2.04$ & $5.57 \pm 1.93$ & $7.26 \pm 1.66^{*}$ \\
\hline Backward & $5.14 \pm 2.49$ & $5.59 \pm 2.20$ & $5.48 \pm 2.43$ & $6.00 \pm 1.91$ \\
\hline \multicolumn{5}{|l|}{ Toulouse-Piéron test } \\
\hline Number of cancellations & $91.95 \pm 33.10$ & $83.68 \pm 27.23$ & $77.70 \pm 25.70$ & $99.43 \pm 31.91^{*}$ \\
\hline Number of errors & $9.59 \pm 7.59$ & $9.50 \pm 8.12$ & $9.04 \pm 11.45$ & $5.43 \pm 5.53$ \\
\hline \multicolumn{5}{|l|}{ WCST } \\
\hline Number of trials & $67.09 \pm 17.10$ & $69.59 \pm 16.19$ & $64.39 \pm 24.44$ & $88.74 \pm 13.69 *, \#$ \\
\hline Number of errors & $61.05 \pm 18.38$ & $58.41 \pm 16.19$ & $59.83 \pm 22.72$ & $39.26 \pm 13.69 *$, \# \\
\hline Categories & $3.59 \pm 2.13$ & $3.77 \pm 1.97$ & $4.09 \pm 2.48$ & $6.35 \pm 2.27^{*, \#}$ \\
\hline
\end{tabular}

Data are presented as means \pm SD. ANOVA for repeated measurement followed by the Duncan post hoc test. $* \mathrm{p} \leq 0.05$ vs. baseline intragroup condition; ${ }^{*} \mathrm{p} \leq 0.05$ vs. postintervention intergroup condition.

\section{Results}

Table 1 shows the characteristics of the sample (age, weight, height and BMI); there were no significant intergroup differences ( $p>0.05$ ). Table 2 presents the results of the cognitive evaluation, comparing values before and after the intervention; the experimental group performed better in the digit symbol, digit span, block design and Toulouse-Piéron subtests; in the WCST, there were more trials, fewer errors and more categories completed. The digit symbol subtest scores of the control group were significantly lower, but no meaningful alterations in any other variables were observed $(p<0.05)$. When the groups were compared after the study period, differences in the following variables were found: digit symbol $(p<0.05)$, digit span forward $(p<0.05)$ and block design $(p=0.05)$ as well as the numbers of trials in the WCST $(\mathrm{p}<0.05)$, errors $(\mathrm{p}<0.05)$ and categories completed $(\mathrm{p}<0.05)$. No alterations were found for the other variables.

Figure 2 shows the results of the analysis of plasma Hcy concentrations; no significant changes in mean total Hcy values were observed ( $p>0.05$ ). Table 3 shows the exercise test results. The comparison of the experimental group before and after the intervention showed differences in the following variables: $\mathrm{VO}_{2}$ at VT-1 intensity (relative and absolute), heart rate and workload at the same intensity as well as diastolic pressure before and after ergospirometric testing. When comparing the groups in the postintervention condition, significant differences were verified between the experimental and the control group in the following variables: peak $\mathrm{VO}_{2}$ (relative and absolute; $\mathrm{p}<0.005$ and $\mathrm{p}<0.05$, respectively), workload as well as $\mathrm{VO}_{2}$ (absolute) at VT-1 intensity ( $\mathrm{p}<0.001$ and $\mathrm{p}<0.005$, respectively) at maximum 
Table 3. Ergospirometric evaluation

\begin{tabular}{|c|c|c|c|c|}
\hline \multirow[b]{2}{*}{ Variables } & \multicolumn{2}{|l|}{ Control group } & \multicolumn{2}{|c|}{ Experimental group } \\
\hline & baseline & after intervention & baseline & after intervention \\
\hline Peak $\mathrm{VO}_{2}, \mathrm{l} \cdot \mathrm{min}^{-1}$ & $1.20 \pm 0.30$ & $1.10 \pm 0.30$ & $1.40 \pm 0.30$ & $1.40 \pm 0.30$ \\
\hline Peak $\mathrm{VO}_{2}, \mathrm{ml} \cdot \mathrm{kg} \cdot \mathrm{min}^{-1}$ & $15.40 \pm 3.90$ & $14.90 \pm 3.70$ & $18.60 \pm 4.80$ & $19.20 \pm 4.20^{\#}$ \\
\hline Maximum heart rate, bpm & $130.10 \pm 16.80$ & $131.00 \pm 24.50$ & $127.50 \pm 22.70$ & $124.70 \pm 16.60$ \\
\hline $\mathrm{VO}_{2}$ at VT- 1 intensity, $\mathrm{l} \cdot \mathrm{min}^{-1}$ & $0.80 \pm 0.30$ & $0.80 \pm 0.30$ & $0.90 \pm 0.30$ & $1.00 \pm 0.20^{*}$ \\
\hline $\mathrm{VO}_{2}$ at VT- 1 intensity, $\mathrm{ml} \cdot \mathrm{kg} \cdot \mathrm{min}^{-1}$ & $11.30 \pm 3.10$ & $13.90 \pm 14.40$ & $12.40 \pm 3.30$ & $14.40 \pm 3.10$ \\
\hline Heart rate at VT-1 intensity, bpm & $107.60 \pm 13.20$ & $107.80 \pm 18.80$ & $102.60 \pm 16.80$ & $109.80 \pm 15.50 *$ \\
\hline Maximum ventilation, $\mathrm{l} \cdot \mathrm{min}^{-1}$ & $49.20 \pm 17.10$ & $46.70 \pm 15.70$ & $54.90 \pm 14.20$ & $56.10 \pm 11.10$ \\
\hline Workload at VT-1 intensity, W & $50.00 \pm 16.80$ & $53.20 \pm 15.60$ & $50.30 \pm 26.80$ & $98.90 \pm 31.50 *$ \\
\hline
\end{tabular}

Data are presented as means \pm SE. ANOVA for repeated measurement followed by the Duncan post hoc test. ${ }^{*} \mathrm{p} \leq 0.05$ vs. baseline intragroup condition; ${ }^{*} \mathrm{p} \leq 0.05$ vs. postintervention intergroup condition.

Fig. 2. Results of the analysis of plasma Hcy concentrations. Bars denote means, whiskers are SD. No statistical differences were observed when the groups were compared.

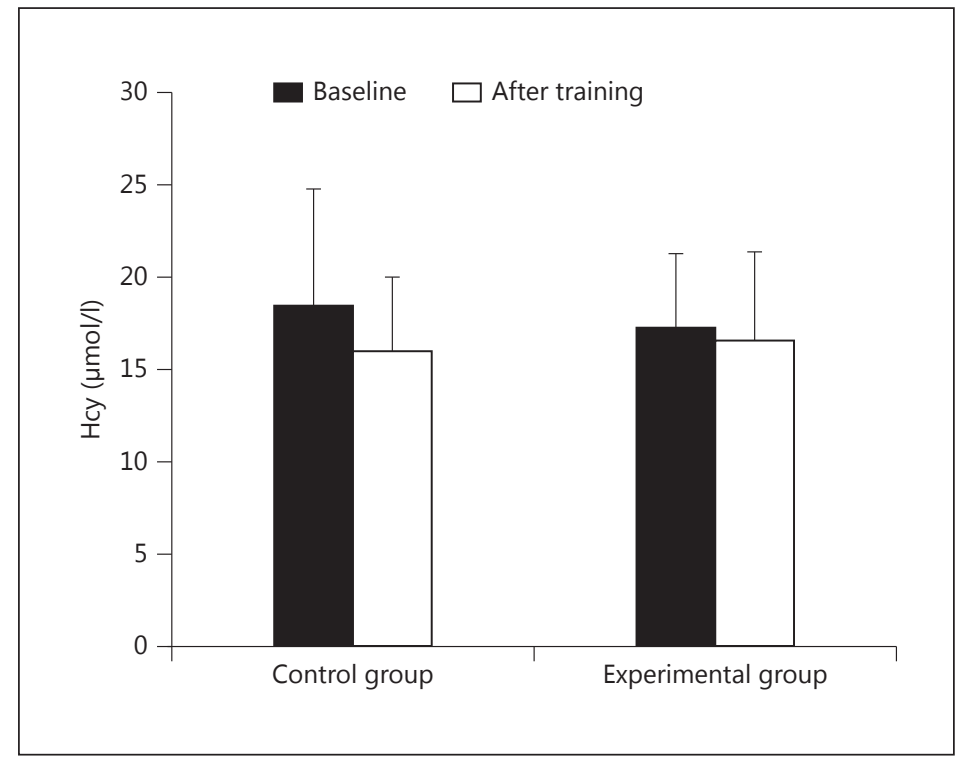

ventilation $(\mathrm{p}<0.05)$. No significant alterations were observed in the other parameters analyzed.

Table 4 shows the metabolic parameters. The serum levels of cholesterol, triglycerides, HDL, glucose, alkaline phosphatase, urea, $\mathrm{T}_{3}, \mathrm{~T}_{4}$ and PSA were significantly increased when compared with those of the control group ( $p<0.05)$.

\section{Discussion}

Our study did not show significant reductions in plasma Hcy concentrations in elderly males after a 6-month endurance exercise program, but the intervention was associated with an improvement in some metabolic markers that may have been responsible for the enhanced cognitive function observed. 
Antunes et al.: Aerobic Physical Exercise Improved the Cognitive Function of Elderly Males but Did Not Modify Their Blood Homocysteine Levels

Table 4. Effect of physical exercise on metabolic parameters

\begin{tabular}{|c|c|c|c|c|}
\hline \multirow[b]{2}{*}{ Variables } & \multicolumn{2}{|l|}{ Control group } & \multicolumn{2}{|c|}{ Experimental group } \\
\hline & baseline & after intervention & baseline & after intervention \\
\hline Uric acid, mg/dl & $6.39 \pm 0.21$ & $6.56 \pm 0.34$ & $5.93 \pm 0.28$ & $6.09 \pm 0.27$ \\
\hline Hemoglobin, g/dl & $15.65 \pm 0.20$ & $15.20 \pm 0.26$ & $15.63 \pm 0.18$ & $15.18 \pm 0.24$ \\
\hline Hematocrit, \% & $46.16 \pm 0.57$ & $46.99 \pm 0.69$ & $45.31 \pm 0.65$ & $44.11 \pm 0.63$ \\
\hline Platelets, $10^{3} / \mathrm{mm}^{3}$ & $217.32 \pm 15.70$ & $211.52 \pm 17.32$ & $229.78 \pm 12.42$ & $218.91 \pm 12.39$ \\
\hline Bilirubin, mg/dl & $0.90 \pm 0.16$ & $0.86 \pm 0.12$ & $1.17 \pm 0.09$ & $0.90 \pm 0.08$ \\
\hline Cholesterol, mg/dl & $207.45 \pm 5.70$ & $199.00 \pm 6.59$ & $195.64 \pm 7.89$ & $173.23 \pm 6.98^{*}, \#$ \\
\hline HDL, mg/dl & $53.59 \pm 3.63$ & $49.33 \pm 3.36^{*}$ & $52.59 \pm 3.42$ & $58.50 \pm 2.11^{*}$ \\
\hline $\mathrm{LDL}, \mathrm{mg} / \mathrm{dl}$ & $127.18 \pm 6.20$ & $123.83 \pm 6.89$ & $118.16 \pm 7.01$ & $114.10 \pm 5.96$ \\
\hline VLDL, mg/dl & $25.99 \pm 2.13$ & $24.62 \pm 2.52$ & $27.79 \pm 3.44$ & $28.56 \pm 2.87$ \\
\hline Creatinine, $\mathrm{mg} / \mathrm{dl}$ & $1.16 \pm 0.04$ & $1.10 \pm 0$ & $1.04 \pm 0.05$ & $0.75 \pm 0.15$ \\
\hline Alkaline phosphatase, U/l & $102.69 \pm 10.43$ & $72.37 \pm 8.38^{*}$ & $100.43 \pm 16.91$ & $71.17 \pm 12.12^{*}$ \\
\hline GGT, U/l & $45.35 \pm 7.71$ & $45.26 \pm 7.38$ & $43.73 \pm 19.03$ & $55.30 \pm 17.19$ \\
\hline SGOT, U/l & $24.57 \pm 1.86$ & $22.78 \pm 1.24$ & $30.38 \pm 3.53$ & $29.13 \pm 3.07$ \\
\hline SGPT, U/l & $27.79 \pm 2.01$ & $26.22 \pm 2.27$ & $31.77 \pm 4.57$ & $30.30 \pm 2.76$ \\
\hline Triglycerides, mg/dl & $143.09 \pm 17.44$ & $138.52 \pm 19.53$ & $150.83 \pm 20.08$ & $107.78 \pm 14.35^{*}$ \\
\hline Urea, mg/dl & $35.58 \pm 2.30$ & $33.48 \pm 1.69$ & $29.15 \pm 1.49$ & $33.28 \pm 1.49$ \\
\hline Glucose, mg/dl & $98.82 \pm 2.55$ & $93.81 \pm 3.10$ & $103.61 \pm 3.26$ & $93.30 \pm 2.66^{*}$ \\
\hline $\mathrm{T}_{3}, \mathrm{ng} / \mathrm{dl}$ & $106.05 \pm 6.14$ & $97.51 \pm 6.58$ & $106.27 \pm 3.74$ & $91.48 \pm 2.62 *$ \\
\hline $\mathrm{T}_{4}, \mathrm{ng} / \mathrm{dl}$ & $8.00 \pm 0.39$ & $7.38 \pm 0.43^{*}$ & $8.08 \pm 0.29$ & $6.59 \pm 0.22 *$ \\
\hline $\mathrm{TSH}, \mu \mathrm{IU} / \mathrm{ml}$ & $3.73 \pm 0.95$ & $3.66 \pm 0.87$ & $2.53 \pm 0.42$ & $2.29 \pm 0.25$ \\
\hline PSA, ng/dl & $1.97 \pm 0.31$ & $1.90 \pm 0.32$ & $2.20 \pm 0.47$ & $1.30 \pm 0.23^{*}$ \\
\hline
\end{tabular}

Data are presented as means \pm SD. ANOVA for repeated measurement followed by the Duncan post hoc test. $* \mathrm{p} \leq 0.05$ vs. baseline intragroup condition; ${ }^{\#} \mathrm{p} \leq 0.05$ vs. postintervention intergroup condition. GGT = $\gamma$-Glutamyl transferase; SGPT = serum glutamic pyruvic transaminase; SGOT = serum glutamic oxaloacetic transaminase; $\mathrm{TSH}$ = thyroid-stimulating hormone.

A study performed in 1999 [28] involving young female subjects that performed an exercise on the cycle ergometer at $60 \%$ of the maximal $\mathrm{VO}_{2}$ showed that acute exercise produces significant increases in plasma Hcy concentrations. In another study [14], the authors found that exercise performed until exhaustion significantly increases Hcy concentrations, but the real effects of physical exercise on Hcy concentrations are not clear. Our results suggest that Hcy may be more related to nutritional factors (appropriate food ingestion or absorption, particularly of vitamins) than to regular physical exercise (endurance), especially in older subjects. A further study demonstrated that continuous physical exercise combined with a high intake of folate and vitamin $\mathrm{B}_{12}$ could be responsible for a reduction of plasma Hcy in middle-aged subjects. Folate, vitamin $\mathrm{B}_{12}$ and vitamin $\mathrm{B}_{6}$ are important cofactors in the metabolic pathways of Hcy [29], and supplementation with folate has been found to be an effective measure to lower plasma Hcy. These data may indicate that our hypothesis that physical exercise alone cannot be responsible for a reduction of Hcy is correct [30].

Hcy concentrations are influenced by vitamin $B_{6}$, vitamin $B_{12}$ and folate status [31]. However, it is important to bear in mind that the aging process involves morphological, functional, biochemical and psychological modifications, and this process may well be associated with reduced renal function and gastric alterations such as higher $\mathrm{pH}$ levels in the stomach, which reduce vitamin $B_{12}$ and folate absorption [2], and this may be reflected in the plasma Hcy concentrations observed. Our study did not monitor diets, so the results should be analyzed with caution; this represents a limitation of our study. 
Antunes et al.: Aerobic Physical Exercise Improved the Cognitive Function of Elderly Males but Did Not Modify Their Blood Homocysteine Levels

It is noteworthy to mention that although our results showed no significant alterations in plasma Hcy concentrations after the endurance exercise program, some volunteers did show a decline in Hcy concentrations (from 24.9 to 14.2, 28.1 to 16.1, 18.4 to 14.1 and 18.8 to $11.1 \mu \mathrm{mol} / \mathrm{l}$, respectively). This finding could suggest that in addition to the dietary factor, regular physical exercise may help to lower Hcy concentrations. Perhaps we did not find statistically significant alterations because of the characteristics of the group we studied: they were healthy seniors who had been sedentary for at least 40 years. It seems unlikely that the relatively short intervention period (6 months) could have the effect of reducing Hcy concentrations, considering the lengthy period of inactivity reported by the subjects. For safety reasons, it would not be appropriate to raise the intensity of the exercise very much, unless there were longer intervention periods to allow this to be done gradually. A further issue that must be considered is that this age group in general has a diminished ability to adapt to physiological stimuli [32].

We also found that there was an improvement in fitness in the experimental group, with improved maximal uptake of oxygen (relative and absolute) and heart rate and workload parameters at VT-1 intensity. Although the exercise was set at a relatively low intensity, there was a significant improvement in the cardiovascular apparatus. According to one study, varying the intensity of physical exercise in relation to VT-1 leads to beneficial alterations in some physiological parameters [33]. Prescribing more intensive exercises leads to a better response to training, thus suggesting that the adaptive response may be intensity dependent. However, the state of the subjects' physical fitness prior to prescription has to be taken into account, particularly for seniors. Long-term sedentary seniors should be put on a lowintensity exercise program.

Hcy is an important marker for cardiovascular disease [2], and some findings indicate that Hcy is involved in cognitive decline $[10,11]$. Hcy may damage brain tissue through multiple pathways and may be directly toxic to vascular endothelial cells or induce their dysfunction, leading to breaching of the blood-brain barrier and altered production of nitric oxide. In addition, if Hcy crosses the blood-brain barrier or is released by cells within the brain, it can act as a potent neurotoxin by directly interacting with plasma membrane components or by intracellular accumulation of S-adenosyl Hcy, inhibiting the methylation of catechol substrates that in turn generate oxyradicals and other cytotoxic, chemically reactive products [34, 35].

On the other hand, several studies have shown that physical exercise is an important means of improving cognitive and cardiovascular function [16, 36]. We found an improvement in cognitive function in our experimental group. Upon comparing its post- and preintervention values, this group developed better attentional processes, short-term working memory and general intelligence. The improved physical fitness of the experimental group may explain this beneficial effect on its cognitive performance. One study [37] suggests that physical exercise maintains vascular integrity and improves the flow of oxygen to the brain, thus making the cognitive process faster and more efficient in physically active individuals through improved cerebral circulation and alterations in neurotransmitter synthesis and degradation. Furthermore, our hypothesis is that the physical exercise increased the plasma levels of brain-derived neurotrophic factor, which plays an important role in neuroplasticity and participates in neural transmission and modulation as well as cell proliferation and neurogenesis, improving cognitive function [38-41]. Exercise can also decrease the expression of the enzyme neuron-specific enolase and the protein S100B that may worsen cognition [42]; the assessment of these variables could be important to explain our results and will be our focus in the future.

Further research is needed to investigate the real effects of regular physical exercise on Hcy. Issues such as the best intensity and/or type of exercise for reducing Hcy concentrations 
Antunes et al.: Aerobic Physical Exercise Improved the Cognitive Function of Elderly Males but Did Not Modify Their Blood Homocysteine Levels

remain unclear. It may well be that better eating and lifestyle habits promote significant changes in these aspects.

Another possible hypothesis regarding cognitive improvement is based on the metabolic profile, which, at least partially, can be improved by physical exercise $[43,44]$ : in the present study, a decrease in alkaline phosphatase levels was observed. According to Vardy et al. [45] and Brown and Thore [46], an increase in alkaline phosphatase levels is associated with Alzheimer's disease and inversely correlated with cognitive function. Furthermore, it appears that alkaline phosphatase is the key enzyme that regulates neurotransmission and thus could play an important role in developmental plasticity and cortical activity, which may possibly be associated with improved cognitive function [47].

Other important aspects for good cognitive function are the relationship between rates of glucose and cholesterol concentrations in the blood. Individuals with high levels of sugar in the blood had lower cognitive ability than those with low sugar levels [48]. Moreover, low total cholesterol levels are associated with cognitive improvement. In the present study, we observed a decrease of glucose and cholesterol levels after 6 months of physical training. These results might partly explain the cognitive improvement observed once the physical exercise had decreased the levels of cholesterol and blood glucose [see also ref. 49-51].

These investigations of the influence of physical exercise on cognitive function have suggested several mechanisms, which could explain relations to different alterations to the human body. This emphasizes the importance of the promotion of physical exercise for the prevention of current diseases (obesity as well as metabolic and cardiovascular diseases) and cognitive decline in humans [52].

Another finding of this study was that physical exercise reduced thyroid hormone levels $\left(\mathrm{T}_{3}\right.$ and $\mathrm{T}_{4}$ ). These reductions may have contributed to the cognitive improvement observed. This observation can be made because hypothyroidism and thyrotoxicosis are already associated with a significant decline in cognitive function, and therapy usually leads to an improvement in these symptoms. In contrast, major affective or cognitive dysfunction is not typical of subclinical thyroid dysfunction. Subtle deficits in specific cognitive domains (primarily working memory and executive function) may exist in subclinical hypothyroidism and thyrotoxicosis, but these are unlikely to cause major problems in most patients [53].

\section{Conclusion}

Our data suggest that a 6-month endurance exercise program does not significantly reduce plasma Hcy concentrations in elderly males, but that the intervention is associated with a substantial improvement in cardiorespiratory fitness and metabolic profile, including cholesterol, triglycerides, HDL, glucose, alkaline phosphatase, urea, $\mathrm{T}_{3}, \mathrm{~T}_{4}$ and PSA, as well as in cognitive function.

\section{Acknowledgments}

All authors are grateful to the Associação Fundo de Incentivo a Pesquisa (AFIP), the Conselho Nacional de Desenvolvimento Cientifico e Tecnológico (CNPq), the Centros de Pesquisa, Expansão e Difusão do Instituto do Sono (CEPID/SONO), the Fundação de Amparo a Pesquisa do Estado de São Paulo (FAPESP) and the Centro de Estudos em Psicobiologia e Exercício (CEPE). Marco Túlio De Mello, Sergio Tufik and Vânia D'Almeida are recipients of CNPq research fellowships. 
Antunes et al.: Aerobic Physical Exercise Improved the Cognitive Function of Elderly Males but Did Not Modify Their Blood Homocysteine Levels

\section{Disclosure Statement}

The authors report no financial relationships relevant to the subjects of this article.

\section{References}

1 Gil-Prieto R, Hernández V, Cano B, Oya M, Gil A: Plasma homocysteine in adolescents depends on the interaction between methylenetetrahydrofolate reductase genotype, lipids and folate: a seroepidemiological study. Nutr Metab (Lond) 2009;6:39.

-2 Schneede J, Refsum H, Ueland PM: Biological and environmental determinants of plasma homocysteine. Semin Thromb Hemost 2000;26:263-279.

-3 Okura T, Miyoshi K, Irita J, Enomoto D, Nagao T, Kukida M, Tanino A, Kudo K, Pei Z, Higaki J: Hyperhomocysteinemia is one of the risk factors associated with cerebrovascular stiffness in hypertensive patients, especially elderly males. Sci Rep 2014;4:1-5.

4 Hankey GJ, Eikelboom JW: Homocysteine and stroke. Curr Opin Neurol 2001;14:95-102.

5 Chiang FF, Wang HM, Lan YC, Yang MH, Huang SC, Huang YC: High homocysteine is associated with increased risk of colorectal cancer independently of oxidative stress and antioxidant capacities. Clin Nutr 2014;33: 1054-1060.

6 Ji Y, Tan S, Xu Y, Chandra A, Shi C, Song B, Qin J, Gao Y: Vitamin B supplementation, homocysteine levels, and the risk of cerebrovascular disease: a meta-analysis. Neurology 2013;15:1298-1307.

7 Wang J, Bai X, Chen Y, Zhao Y, Liu X: Homocysteine induces apoptosis of rat hippocampal neurons by inhibiting 14-3-3ع expression and activating calcineurin. PLoS One 2012;11:e48247.

8 Brattström L, Wilcken DE: Homocysteine and cardiovascular disease: cause or effect? Am J Clin Nutr 2000;72: 315-323.

-9 Piazza F, Galimberti G, Conti E, Isella V, Perlangeli MV, Speranza T, Borroni B, Pogliani EM, Padovani A, Ferrarese C: Increased tissue factor pathway inhibitor and homocysteine in Alzheimer's disease. Neurobiol Aging 2012;2:226-233.

10 Leboeuf R: Homocysteine and Alzheimer's disease. J Am Diet Assoc 2003;103:304-307.

11 Nilsson K: Hyperhomocysteinaemia. A common finding in a psychogeriatric population. Eur J Clin Invest 1996; 26:853-859.

12 Dias VV, Brissos S, Cardoso C, Andreazza AC, Kapczinski F: Serum homocysteine levels and cognitive functioning in euthymic bipolar patients. J Affect Disord 2009;3:285-290.

13 Teunissen CE, Blom AH, Van Boxtel MP, Bosma H, de Bruijn C, Jolles J, Wauters BA, Steinbusch HW, de Vente J: Homocysteine: a marker for cognitive performance? A longitudinal follow-up study. J Nutr Health Aging 2003; 7:153-159.

14 Koning D, Bisse E, Deibert P, Muller HM, Wieland H, Berg A: Influence of training volume and acute physical exercise on the homocysteine levels in endurance-trained men: interactions with plasma folate and vitamin $\mathrm{B}_{12}$. Ann Nutr Metab 2003;47:114-118.

15 De Jong N, Chin A, Paw MJ, de Groot LC, Rutten RA, Swinkels DW, Kok FJ, van Staveren AW: Nutrient-dense foods and exercise in frail elderly: effects on B vitamins, homocysteine, methylmalonic acid, and neuropsychological functioning. Am J Clin Nutr 2001;73:338-346.

-16 Van Boxtel MP, Langerak K, Houx PJ, Jolles J: Self-reported physical activity, subjective health, and cognitive performance in older adults. Exp Aging Res 1996;22:363-379.

17 Baecke JAH, Burema J, Frijters JER: A short questionnaire for the measurement of habitual physical activity in epidemiological studies. Am J Clin Nutr 1982;36:936-942.

18 Wasserman K, MacIlroy MB: Detecting the threshold of anaerobic metabolism in cardiac patients during exercise. Am J Cardiol 1964;14:844-852.

19 Wasserman K, Beaver WL, Whipp BJ: Mechanisms and patterns of blood lactate increase during exercise in man. Med Sci Sports Exerc 1986;18:344-352.

20 Wasserman K, Whipp BJ, Koyl SN, Beaver WL: Anaerobic threshold and respiratory gas exchange during exercise. J Appl Physiol 1973;35:236-245.

-21 Wasserman K: Determinants and detection of anaerobic threshold and consequences of exercise above it. Circulation 1987;76:129-139.

22 Wasserman K, Koike A: Is the anaerobic threshold truly anaerobic? Chest 1992;101:2115-2185.

23 Wechsler D: Wechsler Adult Intelligence Scale, Revised. San Antonio, Psychological Corporation, 1981.

24 Osterrieth PA: Le test de copie d'une figure complexe: contribution à l'étude de la perception et de la mémoire. Arch Psychol 1944;30:286-356.

25 Lezak MD: Neuropsychological Assessment, ed 3. Oxford, Oxford University Press, 1995.

26 Rainho 0: Manual da Bateria CEPA de aptidões específicas. Rio de Janeiro, Centro Editor de Psicologia Aplicada, 1992.

27 Pfeiffer CM, Huff DL, Gunter EW: Rapid and accurate HPLC assay for plasma total homocysteine and cysteine in a clinical laboratory setting. Clin Chem 1999;45:290-292. 
Antunes et al.: Aerobic Physical Exercise Improved the Cognitive Function of Elderly Males but Did Not Modify Their Blood Homocysteine Levels

De Cree C, Malinow MR, Kranenburg GP, Geurten PG, Longford NT, Keizer HA: Influence of exercise and menstrual cycle phase on plasma homocysteine levels in young women - a prospective study. Scand J Med Sci Sports 1999; 9:272-278.

-29 Gaume V, Mougin F, Figard H, Simon-Rigaud ML, N'guyen UN, Callier J, Kantelip JP, Berthelot A: Physical training decreases total plasma homocysteine and cysteine in middle-aged subjects. Ann Nutr Metab 2005;28: 125-131.

-30 Devaraj S, Jialal I: Antioxidants and vitamins to reduce cardiovascular disease. Curr Atheroscler Rep 2000;2: 342-351.

-31 Clarke R, Refsum H, Birks J, Evans JG, Johnston C, Sherliker P, Ueland PM, Schneede J, McPartlin J, Nexo E, Scott JM: Screening for vitamin B-12 and folate deficiency in older persons. Am J Clin Nutr 2003;77:1241-1247.

-32 Rosenberg IH: B vitamins, homocysteine, and neurocognitive functions. Nutr Rev 2001;59:S69-S74.

33 Daley MJ, Spinks WL: Exercise, mobility and aging. Sports Med 2000;29:1-12.

34 Ho PI, Ortiz D, Rogres E, Shea TB: Multiple aspects of homocysteine neurotoxicity: glutamate excitotoxicity, kinase hyperactivation and DNA damage. J Neurosci Res 2002;70:694-702.

35 Zhu BT: On the mechanism of homocysteine pathophysiology and pathogenesis: a unifying hypothesis. Histol Histopathol 2002;17:1283-1291.

-36 Warburton DER, Nicol CW, Bredin SSD: Health benefits of physical activity: the evidence. CMAJ 2006;174: 801-809.

-37 Schuit AJ, Feskens EJ, Launer LJ, Kromhout D: Physical Activity and cognitive decline, the role of apolipoprotein $\varepsilon 4$ allele. Med Sci Sports Exerc 2001;33:772-777.

-38 Russo-Neustadt AA, Chen MJ: Brain-derived neurotrophic factor and antidepressant activity. Curr Pharm Des 2005;11:1495-1510.

-39 Sarbadhikari SN, Saha AK: Moderate exercise and chronic stress produce counteractive effects on different areas of the brain by acting through various neurotransmitter receptor subtypes: a hypothesis. Theor Biol Med Model 2006;23:3-33.

40 Gold SM, Schulz KH, Hartmann S, Mladek M, Lang UE, Hellweg R, Reer R, Braumann KM, Heesen C: Basal serum levels and reactivity of nerve growth factor and brain-derived neurotrophic factor to standardized acute exercise in multiple sclerosis and controls. J Neuroimmunol 2003;1-2:99-105.

41 Ferris LT, Williams JS, Shen CL: The effect of acute exercise on serum brain-derived neurotrophic factor levels and cognitive function. Med Sci Sports Exerc 2007;4:728-734.

$\$ 2$ Al-Jarrah MD, Jamous M: Effect of endurance exercise training on the expression of GFAP, S100B, and NSE in the striatum of chronic/progressive mouse model of Parkinson's disease. NeuroRehabilitation 2011;4:359363.

43 Caro J, Navarro I, Romero P, Lorente RI, Priego MA, Martínez-Hervás S, Real JT, Ascaso JF: Metabolic effects of regular physical exercise in healthy population. Endocrinol Nutr 2013;4:167-172.

-44 Morris C, Grada CO, Ryan M, Roche HM, De Vito G, Gibney MJ, Gibney ER, Brennan L: The relationship between aerobic fitness level and metabolic profiles in healthy adults. Mol Nutr Food Res 2013;7:1246-1254.

45 Vardy ER, Kellett KA, Cocklin SL, Hooper NM: Alkaline phosphatase is increased in both brain and plasma in Alzheimer's disease. Neurodegener Dis 2012;1:31-37.

-46 Brown WR, Thore CR: Review: cerebral microvascular pathology in ageing and neurodegeneration. Neuropathol Appl Neurobiol 2011;1:56-74.

47 Fonta C, Négyessy L, Renaud L, Barone P: Areal and subcellular localization of the ubiquitous alkaline phosphatase in the primate cerebral cortex: evidence for a role in neurotransmission. Cereb Cortex 2004;6:595609.

48 Mõttus R, Luciano M, Starr JM, Deary IJ: Diabetes and life-long cognitive ability. J Psychosom Res 2013;3:275278.

49 Suzuki T, Shimada H, Makizako H, Doi T, Yoshida D, Ito K, Shimokata H, Washimi Y, Endo H, Kato T: A randomized controlled trial of multicomponent exercise in older adults with mild cognitive impairment. PLoS One 2013; 9:e61483.

50 Gordon B, Chen S, Durstine JL: The effects of exercise training on the traditional lipid profile and beyond. Curr Sports Med Rep 2014;4:253-259.

51 Koozehchian MS, Nazem F, Kreider RB, Roberts WJ, Best TM, Rong Y, Zuo L: The effect of physical activity on cognition - physiological mechanisms. Lipids Health Dis 2014;9:95.

52 Gligoroska JP, Manchevska S: The effect of physical activity on cognition - physiological mechanisms. Mater Sociomed 2012;24:198-202.

53 Samuels MH: Thyroid disease and cognition. Endocrinol Metab Clin North Am 2014;2:529-543. 